\title{
Mechanisms regulating resistance to inhibitors of topoisomerase II
}

\section{Ram N. Ganapathi* and Mahrukh K. Ganapathi}

Levine Cancer Institute, Carolinas HealthCare System, Charlotte, NC, USA

Edited by:

Gerald Batist, McGill University,

Canada

\section{Reviewed by:}

Raquel Aloyz, Lady Davis Institute for Medical research; Cancer Segal

Center, Canada

Jean-Yves Masson, Laval University

Cancer Research Center, Canada

\section{${ }^{*}$ Correspondence:}

Ram N. Ganapathi, Levine Cancer

Institute, Carolinas HealthCare

System, 1021 Morehead Medical

Drive, Suite 3100, Charlotte,

NC 28204, USA

e-mail: ram.ganapathi@

carolinashealthcare.org

\begin{abstract}
Inhibitors of topoisomerase II (topo II) are clinically effective in the management of hematological malignancies and solid tumors. The efficacy of anti-tumor drugs targeting topo II is often limited by resistance and studies with in vitro cell culture models have provided several insights on potential mechanisms. Multidrug transporters that are involved in the efflux and consequently reduced cytotoxicity of diverse anti-tumor agents suggest that they play an important role in resistance to clinically active drugs. However, in clinical trials, modulating the multidrug-resistant phenotype with agents that inhibit the efflux pump has not had an impact. Since reduced drug accumulation per se is insufficient to explain tumor cell resistance to topo II inhibitors several studies have focused on characterizing mechanisms that impact on DNA damage mediated by drugs that target the enzyme. Mammalian topo $\| \alpha$ and topo $\| \beta$ isozymes exhibit similar catalytic, but different biologic, activities. Whereas topo $\| \alpha$ is associated with cell division, topo $\| \beta$ is involved in differentiation. In addition to site specific mutations that can affect drug-induced topo IImediated DNA damage, post-translation modification of topo II primarily by phosphorylation can potentially affect enzyme-mediated DNA damage and the downstream cytotoxic response of drugs targeting topo II. Signaling pathways that can affect phosphorylation and changes in intracellular calcium levels/calcium dependent signaling that can regulate site-specific phosphorylation of topoisomerase have an impact on downstream cytotoxic effects of topo II inhibitors. Overall, tumor cell resistance to inhibitors of topo II is a complex process that is orchestrated not only by cellular pharmacokinetics but more importantly by enzymatic alterations that govern the intrinsic drug sensitivity.
\end{abstract}

Keywords: drug resistance, topoisomerase II, calmodulin inhibitors, topo II phosphorylation, casein kinase I

\section{INTRODUCTION}

The emergence of drug-resistant tumor cells continues to be a major problem confronting advances in cancer chemotherapy. Resistance to the various classes of anti-tumor agents (Curt et al., 1984) has been suggested to involve reduced drug accumulation and/or retention, conformational changes and/or over production of the target enzyme, and reduced activation and/or increased catabolism of drug. Doxorubicin (DOX) is a clinically effective anti-tumor agent against a spectrum of neoplastic diseases (Carter, 1975; Myers and Chabner, 1990). Although DOX is an inhibitor of topoisomerase II (topo II), multifactorial mechanisms are involved in the cytotoxic response (Siegfried et al., 1985; Louie et al., 1986; Bhushan et al., 1989; Doroshow et al., 1990). Pioneering studies of Kessel et al. (1968) and Biedler and Riehm (1980) established that reduced drug accumulation in tumor cells is a major mechanism involved in resistance to clinically important anti-tumor agents, e.g., anthracyclines and vinca-alkaloids. The overexpression of P-glycoprotein (PGP) in resistant cells, which mediates energy dependent drug efflux across a concentration gradient and is responsible for reduced drug accumulation, was originally described by Ling and Thompson (1974). The cross-resistance to anti-tumor drugs of diverse structure and/or mechanism of action (Endicott and Ling, 1989; Chin et al., 1993) mediated by PGP is now termed multidrug resistance (MDR). MDR in the absence of overexpression of PGP has been demonstrated to be due to the MDR related protein (MRP), which like PGP also belongs to the ATP-binding cassette (ABC) superfamily of membrane proteins (Center, 1993; Cole et al., 1994).

\section{MODULATION OF DRUG RESISTANCE BY CHEMOSENSITIZERS}

Reduced drug accumulation to anti-tumor drugs of diverse structure and mechanism of action has led to the identification of agents that can potentially sensitize tumor cells with the MDR phenotype. The original reports on modulation of MDR by calcium blockers, e.g., verapamil (Slater et al., 1982; Tsuruo et al., 1982) or calmodulin inhibitors, e.g., trifluoperazine (TFP; Tsuruo et al., 1982; Ganapathi and Grabowski, 1983) has been confirmed subsequently by other laboratories in a variety of model systems (Ford and Hait, 1990). Excellent reviews on compounds modulating the MDR phenotype has been published, and sensitization of drug-resistant pre-clinical tumor models in vivo has been observed (Tsuruo et al., 1982; Ganapathi et al., 1988; Ford and Hait, 1990). The mechanism of action of the "chemosensitizers" in MDR cells is suggested to involve binding to PGP which results in increased drug accumulation and consequently cytotoxicity. While these chemosensitizers do indeed increase drug accumulation, concentrations of the anti-tumor agent required in resistant 
cells are significantly higher than those required by the wildtype (sensitive) cells to achieve equivalent cell kill. Based on the promise from pre-clinical studies, clinical trials have evaluated these agents to sensitize drug refractory tumors (Ganapathi et al., 1993a; Lum etal., 1993) but results with a potent inhibitor of PGP indicate that modulation of drug resistance or enhanced clinical activity is not realized (Carlson et al., 2006; Kolitz et al., 2010).

Most studies on modulation of MDR have relied on tumor models with high levels of resistance making it difficult to ascertain whether the resistance to anthracyclines and vinca alkaloids was exclusively due to overexpression of PGP. In addition, the observation that resistance to lipophilic anthracyclines was observed without apparent differences in drug accumulation between sensitive and resistant cells suggested a role for alternate mechanisms of resistance (Ganapathi etal., 1984, 1989). To assess the central role for PGP and probe mechanisms of resistance to DOX we developed progressively DOX-resistant (5- to 40-fold) cell lines of L1210 mouse leukemia and B16-BL6 mouse melanoma (Ganapathi et al., 1987; Ganapathi and Grabowski, 1988). Studies with these progressively resistant tumor models revealed that while the IC50 for DOX alone was higher with increasing resistance $(0.25-5 \mu \mathrm{M})$, significantly lower concentrations of DOX $(0.08-0.7 \mu \mathrm{M})$ were required in the presence of a non-cytotoxic concentration $(5 \mu \mathrm{M})$ of the calmodulin inhibitor TFP to achieve equivalent cell kill (Ganapathi and Grabowski, 1988; Ganapathi et al., 1988). In the progressively DOX-resistant L1210 cells expression of the MDR phenotype was observed only at $>10$-fold but not at fivefold resistance to DOX and role of PGP in these progressively DOX-resistant cells revealed that: (a) effects of PGP on drug accumulation were correlative with vincristine (VCR) rather than DOX resistance (Ganapathi et al., 1991b, 1993a); and (b) the modulation by TFP of VCR but not DOX cytotoxicity was due to effects on drug accumulation (Ganapathi et al., 1991a,b). Based on the lack of correlation between cellular DOX levels and cytotoxic response, using the progressively DOX-resistant L1210 model system, nuclear levels of DOX were determined following treatment with the IC50 of DOX in the absence or presence of $5 \mu \mathrm{M}$ TFP (Ganapathi et al., 1991a). Results revealed that significantly higher nuclear levels of DOX were required in the resistant compared to the parental sensitive cells to achieve equivalent cytotoxicity, suggesting that alterations in topo II, a putative target of DOX may be involved (Ganapathi et al., 1991a).

\section{TOPOISOMERASE II AND DRUG RESISTANCE}

The topoisomerases alter DNA topology for the efficient processing of genetic material (Chen and Liu, 1994; Pommier et al., 1994; Watt and Hickson, 1994; Froelich-Ammon and Osheroff, 1995). The two well characterized topoisomerases, topoisomerase I (topo I) and topo II, which are essential for DNA metabolism are also the targets for the clinically effective anti-tumor agents, e.g., analogs of camptothecin (topotecan, irinotecan), DOX, daunorubicin, etoposide (VP-16), or teniposide (Chen and Liu, 1994; Pommier et al., 1994; Watt and Hickson, 1994; Froelich-Ammon and Osheroff, 1995). Eukaryotic topo I catalyzes DNA relaxation via a transient single stranded DNA break while topo II will produce a transient double stranded break for the passage of double stranded DNA segments (Chen and Liu, 1994; Pommier et al., 1994; Watt and Hickson, 1994; Froelich-Ammon and Osheroff, 1995). Anti-cancer drugs which interact with topoisomerases and produce DNA strand breaks, involves the stabilization of a ternary complex with DNA. The single or double stranded break induced by topo II, involves linkage to the $5^{\prime}$-phosphoryl end of the broken DNA, with the $5^{\prime}$ broken end protruding precisely four bases with a double strand break (Chen and Liu, 1994; Pommier et al., 1994; Watt and Hickson, 1994; Froelich-Ammon and Osheroff, 1995). The mechanism of DNA strand breakage induced by topo II inhibitors is based on the stabilization of a cleavable complex which is normally a transient reaction intermediate (Chen and Liu, 1994; Froelich-Ammon and Osheroff, 1995). The cleaved intermediate can be either a single strand or double strand break. Drugs which are topo II inhibitors exert their effects possibly by inhibiting the rejoining step in the breakagerejoining cycle, thus shifting the equilibrium toward a cleavable complex (Chen and Liu, 1994; Froelich-Ammon and Osheroff, 1995). The agents which inhibit topo II and stabilize cleavable complex formation can be intercalative, e.g., DOX, amsacrine (m-AMSA), mitoxantrone, or non-intercalative, e.g., VP-16, teniposide (VM-26), and isoflavone derivative genistein (Chen and Liu, 1994; Pommier et al., 1994; Watt and Hickson, 1994; FroelichAmmon and Osheroff, 1995). Mammalian topo II $\alpha$ (170 kDa) and topo II $\beta$ (180 kDa) isozymes exhibit similar catalytic, but different biologic, activities. Whereas topo II $\alpha$ is associated with cell division, topo II $\beta$ is involved in differentiation (Chung et al., 1989; Drake et al., 1989; Woessner et al., 1989, 1990). The $170 \mathrm{kDa}$ topo II isoform is encoded on chromosome 17q21-22 while the $180 \mathrm{kDa}$ topo II isoform is encoded on chromosome 3p24 (Chen and Liu, 1994; Watt and Hickson, 1994). As a target for anticancer agents, there is more information on the interaction with the $170 \mathrm{kDa}$ topo II $\alpha$ protein, although a possible role for alterations in the $180 \mathrm{kDa}$ topo II $\beta$ isoform in mitoxantrone-resistant and m-AMSA-resistant HL-60 cells has been reported (Harker et al., 1991; Chen and Liu, 1994; Froelich-Ammon and Osheroff, 1995; Herzog etal., 1998). A number of in vitro studies using purified or recombinant topo II enzyme have addressed determinants of drug interaction with topo II (Fry et al., 1991; Chen and Liu, 1994; Pommier et al., 1994; Watt and Hickson, 1994; Froelich-Ammon and Osheroff, 1995), and in cell systems the focus has been on enzyme levels as the determinant of drug action (Fry et al., 1991; Chen and Liu, 1994; Pommier et al., 1994; Watt and Hickson, 1994; Froelich-Ammon and Osheroff, 1995). The proliferative state of tumor cells is also an important determinant of sensitivity to inhibitors of topo II, and a correlation exists between proliferation, cell cycle stage and cytotoxicity (Nelson et al., 1986; Sullivan et al., 1986; Estey et al., 1987; D’Arpa et al., 1990).

Resistance to inhibitors of topo II reported in a number of tumor model systems is also prevalent in clinically refractory tumors (Chen and Liu, 1994; Froelich-Ammon and Osheroff, 1995). Based on the evaluation of tumor models with intrinsic or acquired resistance to the topo II inhibitors, as well as cell lines selected for resistance which express decreased levels of topo II (Chen and Liu, 1994; Froelich-Ammon and Osheroff, 1995) it has been proposed that levels of topo II are an important 
determinant of drug sensitivity. Although the levels of enzyme are obviously critical, there are several examples wherein drug sensitivity is not correlative with the $170 \mathrm{kDa}$ topo II $\alpha$ protein level (Ganapathi et al., 1991a, 1996; Chen and Liu, 1994; Pommier et al., 1994; Watt and Hickson, 1994; Froelich-Ammon and Osheroff, 1995). Alternatively, altered sub-cellular distribution of the 170 and $180 \mathrm{kDa}$ isoforms may also be involved with insensitivity to topo II inhibitors (Fernandes et al., 1990; Juenke and Holden, 1993; Mirski et al., 1993; Danks et al., 1994; Feldhoff et al., 1994; Zini et al., 1994). While the identification of a mutant enzyme associated with drug resistance has been reported (Takano et al., 1992; Pommier et al., 1994) an analysis of leukemic cells from patients who have relapsed from etoposide or teniposide therapy revealed that resistance does not have to be associated with mutations in the topo II gene (Danks et al., 1993). Also mutations identified in cultured cell lines were not found in the patient samples (Danks et al., 1993). Point mutations similar to those observed with topo II $\alpha$ in m-AMSA-resistant cell lines (Hinds et al., 1991) has been reported in patients with small cell lung cancer treated with etoposide (Kubo et al., 1996). In addition to these mutations that have possible relevance to patient tumors refractory to therapy, several other mutations in topo II $\alpha$ and $\beta$ (induced or observed in drug-resistant tumor models) have been described that can confer resistance to drugs that target the enzyme (Chikamori et al., 2010). While studies with these mutant forms of topo II are informative, their functional role remains controversial, since they are generally not observed in patients with tumors that are clinically resistant to drugs that target the enzyme.

\section{ANTHRACYCLINES, TOPOISOMERASE II $\alpha$, AND BREAST CANCER}

The recognition that topo II $\alpha$ is a putative target of DOX, a clinically active anthracycline in the treatment of breast cancer, has led to several reports correlating anthracycline sensitivity with topo II $\alpha$ expression. Major focus has been on human epidermal growth factor receptor 2 (HER2) and topo II $\alpha$ expression based on their localization in chromosome 17 as well as determinants of sensitivity to trastuzumab and anthracyclines, respectively. Indeed several reports have established expression of topo II $\alpha$ in predicting sensitivity to adjuvant anthracycline therapy (Oakman et al., 2009; Brase et al., 2010; Kawachi et al., 2010; Di Leo et al., 2011; Du et al., 2011; Nikolényi et al., 2011; O’Malley et al., 2011). The evaluation of tissue inhibitor of metalloproteinase (TIMP-1) with HER2 or topo II $\alpha$ has also suggested that a HT profile (HER2 amplified and/or TIMP-1 negative) or 2T profile (topo II $\alpha$ aberrant and/or TIMP-1 negative) with substantial reduction in mortality but not relapse free survival events following adjuvant anthracycline containing therapy (Ejlertsen et al., 2010; Hertel et al., 2012). Overall, while topo II $\alpha$ expression is possibly a determinant of response to anthracycline containing therapy, robust assay methodology for topo II $\alpha$ and well defined prospective clinical trials will establish the predictive value.

\section{PHOSPHORYLATION OF TOPOISOMERASE II}

The proliferation and cell cycle phase dependent post-translational modification by phosphorylation of the 170 and $180 \mathrm{kDa}$ topo
II protein (Heck et al., 1989; Kroll and Rowe, 1991; Saijo et al., 1992; Burden et al., 1993; Burden and Sullivan, 1994; Kimura et al., 1994a,b), is also linked to increased enzyme activity and DNA cleavable complex formation (Heck et al., 1989; Kroll and Rowe, 1991; Saijo et al., 1992; Burden et al., 1993; Burden and Sullivan, 1994; Kimura et al., 1994a,b). Since phosphorylation of topo II during the cell cycle regulates activity of the enzyme (Ackerman et al., 1985; Sahyoun et al., 1986; Saijo et al., 1990; Cardenas et al., 1992, 1993; Cardenas and Gasser, 1993; Wells et al., 1994), the role of altered topo II phosphorylation in drug resistance has been studied. Takano et al. (1991) reported hyperphosphorylation of topo II in etoposide-resistant cells based on phosphorylation normalized for a 10-fold reduced enzyme level in the etoposide-resistant subline compared to parent cells. Since the phosphorylation of topo II is essential for catalytic events of unknotting and decatenation during cell replication, the observed hyperphosphorylation could represent a compensatory event for the reduced protein level. The topo II $\alpha$ in these etoposide-resistant cells has a Ser861-Phe mutation, suggesting that these cells which hyperphosphorylate topo II $\alpha$, also express mutant serine residue (Kohno et al., 1995). Hypophosphorylation of topo II $\alpha$ in the teniposide-resistant cells was $>$ twofold compared to the parental cells, with serine being the primary phosphorylated amino acid in the sensitive or resistant cells (Chen and Beck, 1995). Subsequent studies by Ritke et al. (1994a, 1995) in etoposide-resistant K562 human leukemia cells have suggested that hypophosphorylation of topo II $\alpha$ in these cells is due to decreased levels of the protein kinase $\mathrm{C}$ isoform $B_{\mathrm{II}}$. Studies in vitro using Drosophila melanogaster topo II have demonstrated that phosphorylation of topo II by casein kinase (CK) II and protein kinase $\mathrm{C}$ can decrease drug stabilized DNA cleavable complex and increase DNA religation, suggesting that phosphorylation can confer relative drug resistance (DeVore et al., 1992). While this effect may be due to the simultaneous use of two different kinases, a role for site specific phosphorylation differences was not discussed. Phosphorylation of topo II $\alpha$ by CKII has also been reported to not affect the DNA relaxing or DNA unknotting activity (Kimura et al., 1996). In contrast to these reports we have demonstrated, following metabolic labeling of cells with $\left[{ }^{32} \mathrm{P}\right]-$ orthophosphoric acid, the hypophosphorylation of $170 \mathrm{kDa}$ topo II in the absence of any decrease in steady state topo II protein levels in three different model systems resistant to topo II inhibitors (Ganapathi et al., 1991a, 1993b, 1996).

\section{FUNCTIONAL ROLE FOR INTRACELLULAR CALCIUM AND SITE-SPECIFIC PHOSPHORYLATION OF TOPOISOMERASE II $\alpha$}

Potential mechanisms affecting reversibility of the drug-induced DNA cleavable complex (Hsiang and Liu, 1989) have been reported, and in resistant sublines a specific role for cleavable complex instability has been suggested (de Jong etal., 1993; Ritke etal., 1994b). The incubation of Chinese hamster DC3F cells in calcium-free medium or chelation of extracellular calcium with [ethylenebis(oxyethylenenitrilo)] tetraacetic acid (EGTA) has been reported to protect against the cytotoxicity of VP-16 (Bertrand et al., 1991). However, under these same conditions, VP-16-induced DNA single strand break frequency in calcium-depleted cells was reported to be comparable to control cells (Bertrand et al., 1991). The amount of phosphorylated topo 
II $\alpha$ in cells is obviously a balance between kinase and phosphatase activity, and our data on hypophosphorylated topo II $\alpha$ in etoposide-resistant cells may be linked to enhanced phosphatase activity. We have previously reported that okadaic acid an inhibitor of protein phosphatases 1 and 2A does not affect the cytotoxicity of the topo II inhibitor DOX (Kawamura et al., 1996b). The activity of protein phosphatase 2B (calcineurin) is enhanced following phosphorylation by calcium-calmodulin protein kinase II (Hashimoto and Soderling, 1989; Sacks et al., 1995) or suppressed by calmodulin inhibitors (Klee et al., 1988). Thus, enhanced phosphorylation of topo II $\alpha$ (Kawamura et al., 1996a) in the presence of the inhibitors of calcium-calmodulin regulated processes, e.g., TFP or 1-[N,O-bis(1,5-isoquinolinesulfonyl)- $\mathrm{N}$ methyl-L-tyrosyl]-4-phenylpiperazine (KN-62) possibly involves inhibition of calcineurin activity, which leads to potentiation of DNA cleavable complex formation and cytotoxicity of topo II inhibitors.

Based on the potentiation of DOX cytotoxicity and DNA damage by TFP and other inhibitors of calcium-calmodulin regulated cellular events we sought to determine whether intracellular calcium could be involved in affecting DNA damage induced by drugs that target topo II. Manipulating intracellular "free" calcium was achieved with the chelator (Gana-

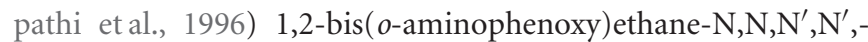
tetraacetic acid tetra(acetoxymethyl) ester (BAPTA-AM). In wildtype cells pre-treatment with BAPTA-AM followed by the topo II inhibitor etoposide (VP-16) led to significant reductions in drug stabilized DNA cleavable complex formation and cytotoxicity (Ganapathi etal., 1996). These results on reduced DNA cleavable complex formation following buffering of intracellular calcium, in general support the original observation of Osheroff and Zechiedrich who reported that in experiments with the purified enzyme in vitro, calcium was able to promote high levels of D. melanogaster topo II-mediated DNA cleavage (Osheroff, 1987; Osheroff and Zechiedrich, 1987). Also, pre-treatment of wildtype cells with BAPTA-AM led to hypophosphorylation of topo II $\alpha$ (Ganapathi et al., 1996). In order to determine whether the hypophosphorylation of topo II $\alpha$ was site-specific, we carried out 2D mapping with tryptic digests of immunoprecipitated topo II $\alpha$ from in DOX-resistant or wild-type cells pre-treated with BAPTAAM (Ganapathi et al., 1996; Chikamori et al., 2003). Interestingly, we found that site specific hypophosphorylation of topo II $\alpha$ in DOX-resistant or wild-type cells pre-treated with BAPTA-AM was comparable (Ganapathi et al., 1996; Chikamori et al., 2003). Using liquid chromatography-tandem mass spectrometry, we identified the hypophosphorylated site as serine 1106 in topo II $\alpha$ (Chikamori et al., 2003).

To establish the functional role for serine 1106 in topo II $\alpha$, mutation of serine 1106 to alanine (S1106A) was carried out and found to abrogate phosphorylation of the phosphopeptides that were found either in the DOX-resistant cells or wild-type cells treated with BAPTA-AM. Using purified wildtype or mutant (S1106A) topo II $\alpha$ expressed in BJ201 cells, we observed decreased decatenation activity as well as etoposide stabilized DNA cleavable complex formation with the mutant enzyme (Chikamori etal., 2003). A functional role in vivo for serine 1106 in resistance to inhibitors of topo II was also established using the yeast system wherein resistance to the cytotoxic effects of etoposide and m-AMSA was observed (Chikamori et al., 2003).

Since serine 1106 is flanked by CKI consensus sequences, and phosphorylation of this site is regulated by calcium, we probed the effect of inhibitors of CKI (Grozav et al., 2009). Treatment with CKI-7 or IC261 that inhibit CKI activity, both hypophosphorylation of serine 1106 and decreased etoposide stabilized DNA cleavable complex formation was observed, suggesting a potential role for CKI phosphorylation of topo II $\alpha$ (Grozav et al., 2009). In the CKI family, a functional role for calcium regulatable $\mathrm{CKI} \delta$ and/or CKI $\varepsilon$ in phosphorylating serine 1106 and affecting drug stabilized topo II DNA cleavable complex formation was established using small interfering RNA (siRNA) that target these isozymes of CKI (Grozav et al., 2009). Although a precise role for site specific hypophosphorylation of topo II $\alpha$ and resistance to inhibitors of topo II in patient tumors has not been established, in our preliminary studies with early passage cultures of acute myeloid leukemia and non-small cell lung cancer from patients, we have observed a correlation of site specific hypophosphorylation of topo II $\alpha$ and decreased drug stabilized DNA cleavable complex formation and/or cytotoxicity with inhibitors that target topo II.

In addition to phosphorylation, other post-translational modifications of topo II include sumoylation and ubiquitination (Chikamori et al., 2010). Sumoylation of topo II that is induced by inhibitors targeting the enzyme also affects cellular localization (Chikamori et al., 2010). A role for ubiquitination-proteasome pathway in regulating enzyme function has also been reported (Chikamori et al., 2010). Interestingly, in human non-small cell lung carcinoma cells, proteasome inhibition with, e.g., MG-132 following treatment with etoposide leads to enhanced apoptosis and decreased arrest of cells in the $\mathrm{G}_{2}+\mathrm{M}$ boundary, without apparent alteration in degradation of topo II (Tabata et al., 2001). In contrast, pre-treatment with the proteasome inhibitor followed by etoposide leads to decreased apoptosis, possibly due effects on apoptotic signaling (Tabata et al., 2001). Neither, pre- or posttreatment with the proteasome inhibitor affected DNA damage induced by etoposide, suggesting that downstream events, e.g., apoptotic response may be another strategy to enhance anti-tumor activity of topo II inhibitors.

\section{FUTURE DIRECTIONS}

In summary, it is apparent that multifactorial mechanisms govern the sensitivity of tumor cells to the DNA damaging and cytotoxic effects of clinically useful inhibitors of topo II. Much progress has been made in identifying agents and developing strategies for enhancing cellular accumulation of topo II inhibitors in tumors with the MDR phenotype. However, differences between "acquired" and "intrinsic" resistance as well as insights on mechanisms that lead to reduced activity of topo II or compromised activation of cell death pathways in tumors from patients resistant to clinically active topo II inhibitors is an underexplored area. Thus, development of targeted drugs that can activate topo II activity and cell death pathways without enhancing treatment-induced toxicity, have considerable potential in combination therapy for clinically improving the anti-tumor efficacy of topo II inhibitors. 


\section{ACKNOWLEDGMENTS}

Authors gratefully acknowledge the valuable contributions of the talented post-doctoral fellows and technicians at the

\section{REFERENCES}

Ackerman, P., Glover, C. V., and Osheroff, N. (1985). Phosphorylation of DNA topoisomerase II by casein kinase II: modulation of eukaryotic topoisomerase II activity in vitro. Proc. Natl. Acad. Sci. U.S.A. 82, 3164-3168. doi: 10.1073/ pnas.82.10.3164

Bertrand, R., Kerrigan, D., Sarang, M., Pommier, Y., et al. (1991). Cell death induced by topoisomerase inhibitors. Role of calcium in mammalian cells Biochem. Pharmacol. 42, 77-85. doi: 10.1016/0006-2952(91)90683-V

Bhushan, A., Kermode, J. C., Posada, J., and Tritton, T. R. (1989). Anthracycline resistance. Cancer Treat. Res. 48, 55-72. doi: 10.1007/978-1-46131601-5_5

Biedler, J. L., and Riehm, H. (1980) Cellular resistance to actinomycin D in Chinese hamster cells in vitro: cross-resistance, radioautographic, and cytogenetic studies. Cancer Res. 30, 1171-1184. doi: 10.1158/10780432.CCR-09-2471

Brase, J. C., Schmidt, M., Fischbach, T., Sültmann, H., Bojar, H., Koelbl, H. et al. (2010). ERBB2 and TOP2A in breast cancer: a comprehensive analysis of gene amplification, RNA levels, and protein expression and their influence on prognosis and prediction. Clin. Cancer Res. 16, 2391-2401. doi: 10.1021/bi00253a001

Burden, D. A., Goldsmith, L. J., and Sullivan, D. M. (1993). Cell-cycledependent phosphorylation and activity of Chinese-hamster ovary topoisomerase II. Biochem. J. 293, 297-304.

Burden, D. A., and Sullivan, D. M. (1994). Phosphorylation of the $\alpha$ - and $\beta$ - isoforms of DNA topoisomerase II is qualitively different in interphase and mitosis in Chinese hamster ovary Cells. Biochemistry 33, 14651-14655. doi: 10.1021/ bi00253a001

Cardenas, M. E., Dang, Q., Glover, C. V., and Gasser, S. M. (1992). Casein kinase II phosphorylates the eukaryotic-specific C-terminal domain of topoisomerase II in vivo. EMBO J. 11, 1788-1796.

Cardenas, M. E., and Gasser, S. M. (1993). Regulation of topoisomerase II by phosphorylation: a role for casein kinase II. J. Cell Sci. 104, 219-225.

Cardenas, M. E., Walter, R., Hanna, D., and Gasser, S. M. (1993). Casein kinase II copurifies with yeast DNA topoisomerase II and re-activates the dephosphorylated enzyme. J. Cell Sci. 104, 533-543.

Carlson, R. W., O’Neill, A. M., Goldstein, L. J., Sikic, B. I., Abramson, N., Stewart, J. A., et al. (2006). A pilot phase II trial of valspodar modulation of multidrug resistance to paclitaxel in the treatment of metastatic carcinoma of the breast (E1195): a trial of the Eastern Cooperative Oncology Group. Cancer Invest. 24, 677-681. doi: 10.1080/07357900600981349

Carter, S. K. (1975). Adriamycin-a review. J. Natl. Cancer Inst. 55, 1265 1274.

Center, M. S. (1993). Non-Pglycoprotein multidrug resistance in cell lines which are defective in the cellular accumulation of drugs. Cytotechnology 12, 109-125. doi: 10.1007/BF00744660

Chen, A. Y., and Liu, L. F. (1994). DNA Topoisomerases; essential enzymes and lethal targets. Annu. Rev. Pharmacol. Toxicol. 36, 191-218. doi: 10.1146/annurev.pa.34.040194. 001203

Chen, M., and Beck, W. T. (1995). DNA topoisomerase II expression, stability, and phosphorylation in two VM26-resistant human leukemic CEM sublines. Oncol. Res. 7, 103-111.

Chikamori, K., Grabowski, D. R., Kinter, M., Willard, B. B., Yadav, S., Aebersold, R. H., et al. (2003). Phosphorylation of serine 1106 in the catalytic domain of topoisomerase II alpha regulatesenzymatic activity and drug sensitivity. J. Biol. Chem. 278, 12696 12702. doi: 10.1074/jbc.M300837200 Chikamori, K., Grozav, A. G. Kozuki, T., Grabowski, D., Ganapathi, R., Ganapathi, M. K., et al. (2010). DNA topoisomerase II enzymes as molecular targets for cancer chemotherapy. Curr. Cancer Drug Targets 10, 758-771. doi: 10.2174/156800910793605785

Chin, K. V., Pastan, I., and Gottesman, M. M. (1993). Function and resistance gene. Adv. Cancer Res. 60, 157-180. doi: 10.1016/S0065230X(08)60825-8

Chung, T. D., Drake, F. H., Tan, K. B. Per, S. R., Crooke, S. T., Mirabelli C. K., et al. (1989). Characterization and immunological identification of cDNA clones encloding two human DNA topoisomerase II isozymes. Proc. Natl. Acad. Sci. U.S.A. 86, 94319435. doi: 10.1073/pnas.86.23.9431 regulation of the human multidrug

Cleveland Clinic Foundation that are summarized in this review. Supported by USPHS Grants RO1 CA35531 and RO1 CA74939.

Cole, S. P., Sparks, K. E., Fraser, K., Loe, D. W., Grant, C. E. Wilson, G. M., etal. (1994) Pharmacological characterization of multidrug resistant MRP-transfected human tumor cells. Cancer Res. 54, 5902-5910.

Curt, G. A., Clendeninn, N. J., and Chabner, B. A. (1984). Drug resistance in cancer. Cancer Treat. Rep. 68, 87-99.

Danks, M. K., Qiu, J., Catapano, C. V., Schmidt, C. A., Beck, W. T., Fernandes, D. J., et al. (1994). Subcellular distribution of the $\alpha$ and $B$ topoisomerase II-DNA complexes stabilized by VM-26. Biochem. Pharmacol. 48, 1785-1795. doi: 10.1016/00062952(94)90465-0

Danks, M. K., Warmoth, M. R., Friche, E., Granzen, B., Bugg, B. Y., Harker, W. G., et al. (1993). Single-strand conformational polymorphism analysis of the $M(r)$ 170,000 isozyme of DNA topoisomerase II in human tumor cells. Cancer Res. 53, 1373 1379.

D’Arpa, P., Beardmore, C., and Liu, L. F. (1990). Involvement of nucleic acid synthesis in cell killing mechanisms of topoisomerase poisons. Cancer Res. 50, 6919-6924.

de Jong, S., Kooistra, A. J., de Vries, E. G., Mulder, N. H., Zijlstra, J. G., et al. (1993). Topoisomerase II as a target of VM-26 and 4'-(9-Acridinylamino) methanesulfon-m-aniside in atypical multidrug resistant human small cell lung carcinoma cells. Cancer Res. 53, 1064-1071.

DeVore, R. F., Corbett, A. H., and Osheroff, N. (1992). Phosphorylation of topoisomerase II by casein kinase II and protein kinase C: effects on enzyme mediated DNA cleavage/religation and sensitivity to the antineoplastic drugs etoposide and 4'-(9-acridinylamino) methanesulfon-m-anisidide. Cancer Res. 52, 2156-2161.

Di Leo, A., Desmedt, C., Bartlett, J. M., Piette, F., Ejlertsen, B., Pritchard, K. I., et al. (2011). HER2 and TOP2A as predictivemarkers for anthracyclinecontaining chemotherapy regimens as adjuvant treatment of breast cancer: a meta-analysis of individual patient data. Lancet Oncol. 12, 1134-1142. doi: 10.1016/S1470-2045 (11)70231-5

Doroshow, J. H., Akman, S., Chu, F. F., and Esworthy, S. (1990) Role of the glutathione-glutathione peroxidase cycle in the cytotoxicity of the anticancer quinones. Pharmacol. Ther. 47, 359-370. doi: 10.1016/0163-7258(90)90062-7

Drake, F. H., Hofmann, G. A., Bartus, H. F., Mattern, M. R., Crooke, S. T., Mirabelli, C. K., et al. (1989). Biochemical and pharmacological properties of p170 and p180 forms of topoisomerase II. Biochemistry 28, 8154-8160. doi: 10.1021/ bi00446a029

Du, Y., Zhou, Q., Yin, W., Zhou, L., Di, G., Shen, Z., et al. (2011). The role of topoisomerase II $\alpha$ in predicting sensitivity to anthracyclines in breast cancer patients: a meta-analysis of published literatures. Breast Cancer Res. Treat. 129, 839-848. doi: 10.1007/s10549-011-1694-9

Ejlertsen, B., Jensen, M. B., Nielsen, K. V., Balslev, E., Rasmussen, B. B., Willemoe, G. L., et al. (2010). HER2, TOP2A, and TIMP-1 and responsiveness to adjuvant anthracyclinecontaining chemotherapy in highrisk breast cancer patients. J. Clin. Oncol. 28, 984-990. doi: 10.1200/JCO.2009.24.1166

Endicott, J. A., and Ling, V. (1989). The biochemistry of P-glycoprotein mediated multidrug resistance. Ann. Rev. Biochem. 58, 137-171. doi: 10.1146/annurev.bi.58.070189.00 1033

Estey, E., Adlakha, R. C., Hittelman, W. N., and Zwelling, L. A. (1987). Cell cycle state dependent variations in drug-induced topoisomerase II mediated DNA cleavage and cytotoxicity. Biochemistry 26, 4338-4344. doi: 10.1021/bi00388a023

Feldhoff, P. W., Mirski, S. E. L., Cole, S. P. C., and Sullivan, D. M. (1994). Altered subcellular distribution of topoisomerase II $\alpha$ in a drug-resistant human small cell lung cancer cell line. Cancer Res. 54, 756-762.

Fernandes, D. J., Danks, M. K., and Beck, W. T. (1990). Decreased nuclear matrix DNA topoisomerase II in human leukemia cells resistant to VM-26 and m-AMSA. Biochemistry 29, 4235-4241. doi: 10.1021/ bi00469a028

Ford, J. M., and Hait, W. N. (1990). Pharmacology of drugs that alter multidrug resistance in cancer. Pharmacol. Rev. 42, 155-199.

Froelich-Ammon, S. J., and Osheroff, N. (1995). Topoisomerase poisons: harnessing the dark side of enzyme mechanism. J. Biol. Chem. 270, 21429-21432. doi: 10.1074/ jbc.270.37.21429 
Fry, A. M., Chresta, C. M., Davies, S. M., Walker, M. C., Harris, A. L., Hartley, J. A., et al. (1991). Relationship between topoisomerase II level and chemosensitivity in human tumor cell lines. Cancer Res. 51, 6592-6595.

Ganapathi, R., Budd, T., and Bukowski, R. (1993a). "Modulation of clinical doxorubicin resistance: application of laboratory concepts and future directions" in The Mechanism and New Approach on Drug Resistance of Cancer Cells, eds T. Miyazaki, F. Takaku, and K. Sakurada (Amsterdam: Elsevier Science Publishers, B.V.), 267-278.

Ganapathi, R., Zwelling, L., Constantinou, A., Ford, J., Grabowski, D., etal. (1993b). Altered phosphorylation, biosynthesis and degradation of the $170 \mathrm{kDa}$ isoform of topoisomerase II in amsacrineresistant human leukemia cells. Biochem. Biophys. Res. Commun. 192, 1274-1280. doi: 10.1006/bbrc.1993 .1554

Ganapathi, R., Constantinou, A., Kamath, N., Dubyak, G., Grabowski, D., Krivacic, K., et al. (1996). Resistance to etoposide in human leukemia HL-60 cells: reduction in drug-induced DNA cleavage associated with hypophosphorylation of topoisomerase II phosphopeptides. Mol. Pharmacol. 50, 243-248.

Ganapathi, R., and Grabowski, D. (1983). Enhancement of sensitivity to Adriamycin in resistant P388 leukemia by the calmodulin inhibitor trifluoperazine. Cancer Res. 43, 36963699.

Ganapathi, R., and Grabowski, D. (1988). Differential effect of the calmodulin inhibitor trifluoperazine in modulating cellular accumulation, retention and cytotoxicity of doxorubicin in progressively doxorubicin resistant L1210 mouse leukemia cells: lack of correlation between cellular doxorubicin levels and expression of resistance. Biochem. Pharmacol. 37, 185193. doi: 10.1016/0006-2952(88) 90716-2

Ganapathi, R., Grabowski, D., Rouse, W., and Riegler, F. (1984). Differential effect of the calmodulin inhibitor trifluoperazine on the cellular accumulation, retention and cytotoxicity of anthracyclines in doxorubicin (adriamycin) resistant P388 mouse leukemia cells. Cancer Res. 44, 50565061.

Ganapathi, R., Grabowski, D., Schmidt, H., Bell, D., and Melia, M. (1987). Characterization, in vitro and in vivo of progressively adriamycinresistant B16-BL6 mouse melanoma cells. Cancer Res. 47, 3464-3468.

Ganapathi, R., Grabowski, D., Sweatman, T. W., Seshadri, R., and Israel, M. (1989). N-benzyl-adriamycin14-valerate versus progressively doxorubicin-resistant murine tumors: cellular pharmacology and characterization of cross-resistance in vitro and in vivo. Br. J. Cancer 60, 819-826. doi: 10.1038/bjc.1989.373

Ganapathi, R., Kamath, N., Constantinou, A., Grabowski, D., Ford, J. Anderson, A., et al. (1991a). Effect of the calmodulin inhibitor trifluoperazine on phosphorylation of $\mathrm{P}$ glycoprotein and topoisomerase II: relationship to modulation of subcellular distribution, DNA damage and cytotoxicity of doxorubicin in multidrug resistant L1210 mouse leukemia cells. Biochem. Pharmacol. 41, R21-R26. doi: 10.1016/00062952(91)90115-L

Ganapathi, R., Kuo, T., Teeter, L., Grabowski, D., and Ford, J. (1991b). Relationship between expression of P-glycoprotein and efficacy of trifluoperazine in multidrug-resistant cells. Mol. Pharmacol. 39, 1-8.

Ganapathi, R., Schmidt, H., Grabowski, D., Melia, M., Ratliff, N., et al. (1988). Modulation in vitro and in vivo of cytotoxicity but not cellular levels of doxorubicin by the calmodulin inhibitor trifluoperazine is dependent on the level of resistance. Br. J. Cancer 58, 335-340. doi: 10.1038/bjc.1988.214

Grozav, A. G., Chikamori, K., Kozuki T., Grabowski, D. R., Bukowski, R. M., Willard, B., et al. (2009). Casein kinase I delta/epsilonphosphorylates topoisomerase IIalpha at serine-1106 and modulates DNA cleavageactivity. Nucleic Acids Res. 37, 382-392. doi: 10.1093/nar/gkn934

Harker, W. G., Slade, D. L., Drake, F. H., and Parr, R. L. (1991). Mitoxantrone resistance in HL-60 leukemia cells: reduced nuclear topoisomerase II catalytic activity and drug-induced DNA cleavage in association with reduced expression of the topoisomerase II beta isoform. Biochemistry 30, 9953 9961. doi: 10.1021/bi00105a020

Hashimoto, Y., and Soderling, T. R. (1989). Regulation of calcineurin by phosphorylation. Identification of the regulatory site phosphorylated by $\mathrm{Ca} 2+/$ calmodulin-dependent protein kinase II and protein kinase C. J. Biol. Chem. 264, 1652416529.

Heck, M. M. S., Goldsmith, L. J., and Sullivan, D. M. (1989). In vivo phosphorylation of the $170-\mathrm{kDa}$ form of eukaryotic DNA topoisomerase II cell cycle analysis. J. Biol. Chem. 264, 15161-15164.

Hertel, P. B., Tu, D., Ejlertsen, B., Jensen, M. B., Balslev, E., Jiang, S., et al. (2012). TIMP-1 in combination with HER2 and TOP2A for prediction of benefit from adjuvant anthracyclines in high-risk breast cancer patients. Breast Cancer Res. Treat. 132, 225-234. doi: 10.1007/s10549-0111896-1

Herzog, C. E., Holmes, K. A., Tuschong, L. M., Ganapathi, R., and Zwelling, L. A. (1998). Absence of topoisomerase IIß in an amsacrine-resistant human leukemia cell line with mutant topoisomerase II $\alpha$. Cancer Res. 58, 52985300.

Hinds, M., Deisseroth, K., Mayes, J., Altschuler, E., Jansen, R., Ledley, F. D., et al. (1991). Identification of a point mutation in the topoisomerase II gene from a human leukemia cell line containing an amsacrineresistant form of topoisomerase II. Cancer Res. 51, 4729-4733.

Hsiang, Y.-W., and Liu, L. F. (1989). Evidence for the reversibility of cellular DNA lesion induced by mam malian topoisomerase II poisons. J. Biol. Chem. 264, 9713-9715.

Juenke, J. M., and Holden, J. A. (1993). The distribution of DNA topoisomerase II isoforms in differentiated adult mouse tissues. Biochim. Biophys. Acta. 1216, 191-196. doi: 10.1016/0167-4781(93)90144-3

Kawachi, K., Sasaki, T., Murakami, A., Ishikawa, T., Kito, A., Ota, I., etal. (2010). The topoisomerase II alpha gene status in primary breast cancer is a predictive marker of the response to anthracycline-based neoadjuvant chemotherapy. Pathol. Res. Pract. 206, 156-162. doi: 10.1016/j.prp.2009.10.009

Kawamura, K., Grabowski, D., Krivacic, K., Hidaka, H., Ganapathi, R., et al. (1996a). Cellular events involved in the sensitization of etoposideresistant cells by inhibitors of calcium-calmodulin-dependent processes. Role for effects on apoptosis, DNA cleavable complex, and phosphorylation. Biochem. Pharmacol. 52, 1903-1909. doi: 10.1016/S00062952(96)00692-2

Kawamura, K. I., Grabowski, D., Weizer, K., Bukowski, R., Ganapathi, R., et al. (1996b). Modulation of vinblastine cytotoxicity by dilantin (phenytoin) or the protein phosphatase inhibitor okadaic acid involves the potentiation of anti-mitotic effects and induction of apoptosis in human tumour cells. Br. J. Cancer 732, 183-8. doi: 10.1038/bjc. 1996.33
Kessel, D., Botterill, V., and Wodinsky, I. (1968). Uptake and retention of daunomycin by mouse leukemic cells as factors in drug response. Cancer Res. 28, 938-941.

Kimura, K., Nozaki, N., Saijo, M., Kikuchi, A., Ui, M., and Enomoto, T. (1994a). Identification of the nature of modification that causes the shift of DNA topoisomerase IIß to apparent higher molecular weight forms in the M Phase. J. Biol. Chem. 269, 24523-24526.

Kimura, K., Saijo, M., Ui, M., and Enomoto, T. (1994b). Growth stateand cell cycle-dependent fluctuation in the expression of two forms of DNA topoisomerase II and possible specific modification of the higher molecular weight form in the $\mathrm{M}$ phase. J. Biol. Chem. 269, 11731176.

Kimura, K., Saijo, M., Tanaka, M., Enomoto, T., et al. (1996). Phosphorylation-independent stimulation of DNA topoisomerase II $\alpha$ activity. J. Biol. Chem. 271, 1099010995. doi: 10.1074/jbc.271.18.10990

Klee, C. B., Draetta, G. F., and Hubbard, M. J. (1988). Calcineurin. Adv. Enzymol. 61, 149-200.

Kohno, K., Danks, M. K., Matsuda, T., Nitiss, J. L., Kuwano, M., and Beck, W. T. (1995). A novel mutation of DNA-topoisomerase II-alpha gene in an etoposide-resistant human cancer cell line. Cell. Pharmacol. 2, 87-90.

Kolitz, J. E., George, S. L., Marcucci, G., Vij, R., Powell, B. L., Allen, S. L., et al. (2010). P-glycoprotein inhibition using valspodar (PSC-833) does not improve outcomes for patients younger than age 60 years with newly diagnosed acute myeloid leukemia: Cancer and Leukemia Group B study 19808. Blood 116, 1413-1421. doi: 10.1182/blood-2009-07-229492

Kroll, D. J., and Rowe, T. C. (1991). Phosphorylation of DNA topoisomerase II in a human tumor cell line. J. Biol. Chem. 266, 79577961.

Kubo, A., Yoshikawa, A., Hirashima, T., Masuda, N., Takada, M., Takahara, J., et al. (1996). Point mutations of the topoisomerase II $\alpha$ gene in patients with small cell lung cancer treated with etoposide. Cancer Res. 56, 1232-1236.

Ling, V., and Thompson, L. H. (1974). Reduced permeability of CHO cells as a mechanism of resistance to colchicine. J. Cell. Physiol. 83, 103116. doi: 10.1002/jcp.1040830114

Louie, K. G., Hamilton, T. C., Winker, M. A., Behrens, B. C., Tsuruo, T., Klecker, R. W. Jr., et al. (1986). Adriamycin accumulation 
and metabolism in adriamycinsensitive and -resistant human ovarian cancer cell lines. Biochem. Pharmacol. 35, 467-472. doi: 10.1016/0006-2952(86)90221-2

Lum, B. L., Fisher, G. A., Brophy, N. A., Yahanda, A. M., Adler, K. M., Kaubisch, S., et al. (1993). Clinical trials of modulation of multidrug resistance. Pharamcokinetic and pharmacodynamic considerations. Cancer 72, 3502-3514. doi: 10.1002/1097-0142(19931201)72:11

Mirski, S. E. L., Evans, C. D., Almquist, K. C., Slovak, M. L., and Cole, S. P. C. (1993). Altered topoisomerase II $\alpha$ in a drug-resistant small cell lung cancer cell line selected in VP-16. Cancer Res. 53, 4866-4873.

Myers, C. E., and Chabner, B. A. (1990). "Anthracyclines," in Cancer Chemotherapy: Principles and Practice, eds B. A. Chabner and J. M. Collins (Philadelphia: J.B. Lippincott Co.), 356-381.

Nelson, W. G., Liu, L. F., and Coffey, D. S. (1986). Newly replicated DNA is associated with DNA topoisomerase II in cultured rat prostatic adenocarcinoma cells. Nature 322, 187-189. doi: $10.1038 / 322187 \mathrm{a} 0$

Nikolényi, A., Sükösd, F., Kaizer, L., Csörgo, E., Vörös, A., Uhercsák, G., et al. (2011). Tumor topoisomerase II alpha status and response to anthracycline-based neoadjuvant chemotherapy in breast cancer. Oncology. 80, 269-277. doi: $10.1159 / 000329038$

Oakman, C., Moretti, E., Galardi, F., Santarpia, L., and Di Leo, A. (2009). The role of topoisomerase II alpha and HER-2 in predicting sensitivity to anthracyclines in breast cancer patients. Cancer Treat. Rev. 35, 662-667. doi: 10.1016/j.ctrv.2009.08. 006

O'Malley, F. P., Chia, S., Tu, D., Shepherd, L. E., Levine, M. N., Huntsman, D., et al. (2011). Topoisomerase II alpha protein and responsiveness of breast cancer to adjuvant chemotherapy with $\mathrm{CEF}$ compared to CMF in the NCIC CTG randomized MA.5 adjuvant trial. Breast Cancer Res. Treat. 128, 401-409. doi: 10.1007/s10549-0111511-5

Osheroff, N. (1987). Role of divalent cation in topoisomerase II mediated reactions. Biochemistry 26, 6402 6406. doi: 10.1021/bi00394a015
Osheroff, N., and Zechiedrich, E. L. (1987). Calcium-promoted DNA cleavage by eukaryotic topoisomerase II: trapping the covalent enzymeDNA complex in an active form. Biochemistry 26, 4303-4309. doi: 10.1021/bi00388a018

Pommier, Y., Leteurtre, F., Fesen, M R., Fujimori, A., Bertrand, R., Solary, E., et al. (1994). Cellular determinants of sensitivity and resistance to DNA topoisomerase inhibitors. Cancer Invest. 12, 530-542. doi: 10.3109/07357909409021413

Ritke, M. K., Murray, N. R., Allan, W. P., Fields, A. P., and Yalowich, J. C. (1994a). Reduced phosphorylation of topoisomerase II in etoposide-resistant human leukemia K562 Cells. Mol. Pharmacol. 46, 58-66.

Ritke, M. K., Roberts, D., Allan, W. P. Raymond, J., Bergoltz, V. V., Yalowich, J. C., et al. (1994b). Altered stability of etoposide-induced topoisomerase IIDNA complexes in resistant human leukaemia K562 cells. Br. J. Cancer 69, 687-697. doi: 10.1038/bjc. 1994.131

Ritke, M. K., Murray, N. R., Allan W. P., Fields, A. P., and Yalowich, J. C. (1995). Hypophosphorylation of topoisomerase II in etoposide(VP16)-resistant human leukemia K562 cells is associated with reduced levels of $B_{\text {II }}$ protein kinase C. $\mathrm{Mol}$. Pharmacol. 48, 798-805.

Sacks, D. B., Mazus, B., and Joyal, J. L. et al. (1995). The activity of calmodulin is altered by phosphorylation: modulation of calmodulin function by the site of phosphate incorporation. Biochem. J. 312, 197-204.

Sahyoun, N., Wolf, M., Besterman, J., Hsieh, T., Sander, M., LeVine, H. III., et al. (1986). Protein kinase C phosphorylates topoisomerase II: Topoisomerase activation and its possible role in phorbol ester-induced differentiation of HL-60 cells. Proc Natl. Acad. Sci. 83, 1603-1607. doi: 10.1073/pnas.83.6.1603

Saijo, M., Enomoto, T., Hanaoka, F., and Ui, M. (1990). Purification and characterization of type II DNA topoisomerase from mouse FM3A cells: phosphorylation of topoisomerase II and modification of its activity. Biochemistry 29, 583-590. doi: 10.1021/bi00454a036

Saijo, M., Ui, M., and Enomoto, T. (1992). Growth state and cell cycle dependent phosphorylation of DNA topoisomerase II in swiss 3T3 cells. Biochemistry 31, 359-363. doi: 10.1021/bi00117a007

Siegfried, J. M., Burke, T. G., and Tritton, T. R. (1985). Cellular transport of anthracyclines by passive diffusion. Implications for drug resistance. Biochem. Pharmacol. 34, 593598. doi: 10.1016/0006-2952(85) 90251-5

Slater, L. M., Murray, S. L., Wetzel, M. W., Wisdom, R. M., and DuVall, E. M. (1982). Verapamil restoration of daunorubicin responsiveness in daunorubicin resistant Ehrlich ascites carcinoma. J. Clin. Invest. 70, 11311134. doi: 10.1172/JCI110702

Sullivan, D. M., Glisson, B. S., Hodges, P. K., Smallwood-Kentro, S., and Ross, W. E. (1986). Proliferation dependence of topoisomerase II mediated drug action. Biochemistry 25, 22482256. doi: 10.1021/bi00356a060

Tabata, M., Tabata, R., Grabowski, D. R., Bukowski, R. M., Ganapathi, M. K., Ganapathi, R., et al. (2001). Roles of NF-kappaB and 26 S proteasome in apoptotic cell death induced by topoisomerase I and II poison in human non-small cell lung carcinoma. J. Biol. Chem. 276, 8029-8036. doi: 10.1074/jbc.M009831200

Takano, H., Kohno, K., Matsuo, K. Matsuda, T., and Kuwano, M. (1992) DNA topoisomerase-targeting antitumor agents and drug resistance. AntiCancer Drugs 3, 323-330. doi: 10.1097/00001813-19920800000002

Takano, H., Kohno, K., Ono, M., Uchida, Y., and Kuwano, M. (1991). Increased phosphorylation of DNA topoisomerase II in etoposideresistant mutants of human cancer KB Cells. Cancer Res. 51, 3951-3957.

Tsuruo, T., Iida, H., Tsukagoshi, S. and Sakurai, Y. (1982). Increased accumulation of vincristine and adriamycin in drug-resistant P388 tumor cells following incubation with calcium antagonists and calmodulin inhibitors. Cancer Res. 42, 47304733.

Watt, P. M., and Hickson, I. D. (1994) Structure and function of type II DNA topoisomerases. Biochem. 303, 681-695.

Wells, N. J., Addison, C. M., Fry, A. M., Ganapathi, R., and Hickson, I. D. (1994). Serine 1524 is a major site of phosphorylation on human topoisomerase II $\alpha$ protein in vivo and is a substrate for casein kinase II in vitro. J. Biol. Chem. 269, 2974629751.

Woessner, R. D., Chung, T. D., Hofmann, G. A., Mattern, M. R., Mirabelli, C. K., Drake, F. H., et al. (1990). Differences between normal and ras-transformed NIH-3T3 cells in expression of the $170 \mathrm{kD}$ and $180 \mathrm{kD}$ forms of topoisomerase II. Cancer Res. 50, 2901-2908.

Woessner, R. D., Mattern, M. R., Mirabelli, C. K., Johnson, R. K., and Drake, F. H. (1989). Proliferation and cell cycle-dependent differences in expression of the 170 kilodalton and 180 kilodalton forms of topoisomerase II in NIH3T3 cells. Cell Growth Differ. 2, 209-216.

Zini, N., Santi, S., Ognibene, A., Bavelloni, A., Neri, L. M., Valmori, A., et al. (1994). Discrete localization of different DNA topoisomerases in HeLa and K562 cell nuclei and subnuclear fractions. Exp. Cell Res. 210, 336-348. doi: 10.1006/excr. 1994.1046

Conflict of Interest Statement: The authors declare that the research was conducted in the absence of any commercial or financial relationships that could be construed as a potential conflict of interest.

Received: 02 January 2013; accepted: 24 June 2013; published online: 01 August 2013.

Citation: Ganapathi RN and Ganapathi MK (2013) Mechanisms Regulating Resistance to Inhibitors of Topoisomerase II. Front. Pharmacol. 4:89. doi: 10.3389/ fphar.2013.00089

This article was submitted to Frontiers in Pharmacology of Anti-Cancer Drugs, a specialty of Frontiers in Pharmacology. Copyright: () 2013 Ganapathi and Ganapathi. This is an open-access article distributed under the terms of the Creative Commons Attribution License (CC BY). The use, distribution or reproduction in other forums is permitted, provided the original author(s) or licensor are credited and that the original publication in this journal is cited, in accordance with accepted academic practice. No use, distribution or reproduction is permitted which does not comply with these terms. 